\title{
Psicoanálisis y sociología: la perspectiva contrahegemónica de Erich Fromm para el estudio de la salud mental*
}

\author{
Eric Fromm's Counter-Hegemonic Perspective for the Study of \\ Mental Health
}

Psicanálise e sociologia: a perspectiva contra-hegemônica de Erich Fromm para o estudo da saúde mental

Clarisbel Gómez Vasallo**

\section{RESUMEN}

La reflexión que en este espacio se presenta aborda la contemPalabras clave: poraneidad del pensamiento del sociólogo, psicólogo y filósopsicoanálisis, salud fo alemán Erich Fromm para el estudio de la salud mental. Las mental, sociología. crecientes preocupaciones por esta área de la salud, tanto en la agenda de las ciencias médicas como sociales y políticas, dentro y fuera de nuestra región, constituyen una de las principales motivaciones de estas líneas. El interés fundamental de la autora ha estado en intentar visualizar la utilidad teórica y metodológica de los estudios de este autor para el análisis empírico de dicha problemática, en tanto este favorecería los acercamientos a la misma desde una comprensión que no parcele la totalidad humana y su relación con la naturaleza. Constituye este artículo el resultado de los primeros avances de los estudios doctorales de la autora, enfrascados en un análisis de las relaciones que se tejen entre diversos factores sociales y el continuo salud-enfermedad mental en una cohorte de población en edad laboral de la capital cubana. Las dimensiones estadísticas de esta problemática en Cuba y los incipientes acercamientos hechos desde la sociología en el contexto cubano a la misma devienen también en razones que han impulsado este inicio.

Avances del informe de investigación doctoral. Departamento de Sociología, Universidad de La Habana, Cuba.

** Master en Sociología. Departamento de Sociología de la Universidad de la Habana, Cuba.E-mail: clarisbel.gomez@ffh.uh.cu 


\begin{abstract}
The reflection presented in this space addresses the contemporary thinking of German sociologist, psychologist, and philosopher Erich Fromm for the study of mental health. The growing concerns about this area of healthcare, both in the medical agenda and the social and political sciences agenda, inside and outside our region, constitute one of the main motivations of this text. The author's fundamental interest has been to visualize the theoretical and methodological utility of Fromm's studies for the empirical analysis of this issue, as this would favor an understanding that does not divide up human totality and its relationship with nature. This article constitutes the result of the first advances of the author's doctoral studies, focused on an analysis of the intertwined relationship between various social factors and the mental health-illness continuum in a cohort of the working-age population in the Cuban capital of Havana. The statistical dimensions of this problem in Cuba and the incipient approaches taken by sociology in the Cuban context, have also become reason to drive this beginning study.
\end{abstract}

\section{RESUMO}

A reflexão apresentada neste espaço aborda a contemporaneidade do pensamento do sociólogo, psicólogo e filósofo alemão Erich Fromm para o estudo da saúde mental. A crescente preocupação por esta área da saúde, tanto na agenda das ciências médicas quanto sociais e políticas, dentro e fora de nossa região, constitui uma das principais motivações deste documento. O interesse fundamental da autora foi tentar visualizar a utilidade teórica e metodológica dos estudos deste autor para a análise empírica desta problemática, na medida em que este favoreceria as aproximações à mesma a partir de uma compreensão que não dividisse a totalidade humana e sua relação com a natureza. Este artigo constitui o resultado dos primeiros avanços dos estudos de doutorado da autora, concentrados em uma análise das relações tecidas entre diversos fatores sociais e a contínua dualidade saúde-doença mental em uma coorte da população em idade laboral da capital cubana. As dimensões estatísticas desta problemática em Cuba e as incipientes abordagens feitas a partir da sociologia no contexto cubano com a mesma se convertem também em razões que impulsionaram este início.
Keywords: psychoanalysis, mental health, sociology.

Palavras-chave: psicanálise, saúde mental, sociologia. 


\section{Razones de un análisis}

Toda reflexión intelectual lleva el sello ineludible de una preocupación, la impresión de una inquietud, la búsqueda de respuestas. Las incertidumbres que han moldeado las cuartillas que conforman la presente, han estado, sobre todo, provocadas por las escasas investigaciones que en el contexto cubano se acercan al estudio de la salud mental desde una perspectiva sociológica y, dado este estado, la necesidad de hallar fundamentos viables para imprescindibles análisis empíricos de un fenómeno que, en Cuba y Latinoamérica, en sentido general, ha tomado dimensiones cada vez más alarmantes (Organización Panamericana de la Salud \& Organización Mundial de la Salud, 2017).

En este sentido, repensar la utilidad del psicoanálisis como perspectiva analítica, como centro de encuentro entre psicología y sociología, alumbra un camino posible para comenzar a desandar senderos trillados y abrir nuevos atajos. Para la sociología cubana constituye esta una tarea pendiente para la que comenzar a visualizar posibles puntos de partida deviene, más que necesario, impostergable.

Con estos motivos de inicio, se propone en las próximas líneas un acercamiento a uno de los desarrollos más notables del psicoanálisis de la segunda mitad del pasado siglo, cuya singular perspectiva crítica hacia las sociedades contemporáneas revela una vigencia incuestionable, revelando una visión casi profética de nuestro presente. Así, la singularidad de los fundamentos epistemológicos de Erick Fromm deviene, para un esfuerzo como el señalado, en piedra de base relevante. Este, unido a otras propuestas de análisis, como los desarrollos contemporáneos de la epidemiología crítica (Breilh, 2003) y los de la Comisión de Determinantes Sociales de la Organización Mundial de la Salud (Organización Mundial de la Salud, 2008), han de constituir pilares teóricos de significativa importancia para una comprensión sociológica del continuo salud-enfermedad mental que supere los acercamientos tradicionales parcelados a esta esfera de la salud humana.

De igual manera, la necesidad de repensarnos a nosotros mismos, de comprendernos como productos contextuales y, a la vez, sujetos edificadores de nuestras realidades, nos conduce a intentar entender las constantes transformaciones de nuestra cotidianidad y nuestro lugar dentro de ellas. Una comprensión sociológica de estos nexos nos 
permite visualizar nítidamente las relaciones que se tejen entre los sistemas socio-estructurales que nos constriñen y nuestro "mundo de la vida" en su sentido fromniano y habermasiano.

\section{Punto de encuentro del psicoanálisis, la sociología y la epidemiología psiquiátrica}

Comprender la salud mental como un continuo es uno de los principales aportes del psicoanálisis en este campo de estudio (De la Cuesta et al, 2009). Desde que a mediados del siglo XIX las relaciones entre la salud y lo social devinieron en preocupación para prominentes médicos y salubristas, los límites de lo exclusivamente biológico fueron puestos en entredicho aun cuando prevaleció, por mucho tiempo, una perspectiva positivista que en la búsqueda de una mayor "cientificidad" intentó desdibujar las contribuciones que desde otros enfoques se erigían.

Cuando a finales del siglo XIX Freud publica sus primeros escritos que intentan superar la psicología clásica, al situar la comprensión de lo individual en sus marcos familiares y en sus relaciones con sus semejantes, e intentando establecer pautas para el análisis de lo sano a partir de lo patológico, abriría el camino para una sociología psicológica que pronto echó profundas raíces en contextos académicos tanto europeos como del otro lado del Atlántico (Montejo, 2009). En este sentido, encontramos dentro de los más conocidos seguidores de Freud tanto a psicólogos como antropólogos, psiquiatras y sociólogos, los que, unas veces fieles a sus conceptos y, en otras, en abierta rebeldía y reconstrucción de sus perspectivas, fueron dotando al psicoanálisis de herramientas para la comprensión de las interrelaciones que se tejen entre los individuos y sus contextos sociales, a la vez que contribuyeron a una comprensión cada vez más multidimensional de lo social como totalidad.

Las más influyentes reelaboraciones del psicoanálisis, que vinieron de la mano de intelectuales como Lacan, Erikson, Cooley, Sullivan, Karen Horney, Moreno y Fromm, entre otros (Bastide, 1961), han tenido a lo largo del desarrollo de este modo de hacer no pocas críticas. Unas han estado realizadas desde posiciones acérrimas que, en defensa de la bandera "más" científica de los métodos empíricos experimentales que van en la búsqueda de explicaciones del tipo causa-efecto, han 
intentado despojar al psicoanálisis, desde el punto de vista epistemológico, de la validez del conocimiento que construye; y otras han sido elaboradas dentro del propio pensamiento psicoanalítico al posicionarse en una u otra perspectiva al interior del mismo en sus intentos de autosuperación. Unos y otros han impulsado, de cierto modo, el desarrollo de esta perspectiva aun en sus momentos más grises, en los que se han cuestionado muchos de los postulados de la escuela ortodoxa.

Además de ello, dentro de los resultados positivos de estos procesos está el de consolidar el acercamiento de diferentes visiones disciplinares, como las de la psiquiatría y la sociología. Los vínculos que en este devenir se han tejido entre estos campos científicos han sido relevantes para uno y otro, en tanto la primera ha comprendido mejor la manera en que los procesos y situaciones psíquicas grupales e individuales están indisolublemente ligadas a sus contextos sociales; y la segunda ha podido entender con mayor claridad cómo las sociedades son inteligibles sin la acertada aprehensión de los que sucede al interior de la psiquis humana y sus interrelaciones con otros y con las estructuras sociales. Como resultado de estos esfuerzos, algunos han llegado a afirmar que "el psiquíatra debe comenzar por ser, necesariamente, sociólogo" (Bastide, 1961, p. 148).

Así, no han sido pocos los autores que se han interesado por visualizar los nexos entre estas dos disciplinas ${ }^{3} \mathrm{y}$, aunque cada uno con intereses diversos, han contribuido a perfilar importantes puntos de encuentro que devienen en fundamentos relevantes para acercamientos contemporáneos más acertados para el estudio del continuo saludenfermedad mental. Los mismos han posibilitado, sin dudas, el hecho de que entrado el siglo XXI se comparta, cada vez más, la concepción epistemológica que sostiene que los factores que intervienen en la sa-

\footnotetext{
$3 \quad$ El interés por visualizar la manera en que estas dos disciplinas se correlacionaban se percibe desde los primeros momentos del desarrollo institucional del psicoanálisis y su expansión internacional. En este sentido, vemos dicha intención en autores tan diversos como el francés G. Gurvitch, algunos de los sociólogos de la Escuela Ecologista de Chicago como William Thomas y Florian Znaniecki, en los desarrollos del interaccionismo simbólico de G. H. Mead y H. Blumer, en la propuesta analítica de C. H. Cooley y en desarrollos marxistas de la teoría crítica franckfurtiana de Erick Fromm. Asimismo, después de la década de 1960, momento en el que hay un renovado interés por el psicoanálisis, desde el punto de vista metodológico y terapeútico, autores como Roger Bastide, H. Ruitenbeck y H. Marcuse desarrollaron importantes esfuerzos en este sentido. Ver Bastide (1961), Ruitenbeck (1973) y Marcuse (1984).
} 
lud mental son indiscutiblemente el resultado híbrido ${ }^{4}$ de procesos biológicos, genéticos, psicológicos, antropológicos, sociales y ambientales. En los marcos de esta, el rescate del psicoanálisis crítico o humanista $^{5}$ se convierte en un instrumento útil para el estudio empírico de los procesos de salud-enfermedad mental, dotándoles sobre todo de un método loable no solo para la clínica, donde ha encontrado sus mayores desarrollos, sino que para cubrir las lagunas que aún persisten en la comprensión de las estrategias de estudios epidemiológicos de esta área de la salud y su necesaria repercusión en los procesos asistenciales (Borges, Medina-Mora \& López-Moreno, 2004).

Si bien en sus inicios el psicoanálisis estuvo concentrado en evidenciar los vínculos entre comportamientos normales y patológicos con la estructura libidinosa y el inconsciente humano (Freud, 1991), y la manera en que esta es moldeada por la familia y la sociedad, en su evolución epistemológica se fueron definiendo cada vez más la relevancia de otros factores sociales, antropológicos y psicológicos. Aunque el devenir de dicha perspectiva no ha estado exenta de fuertes contradicciones, incluso contrapuestas (Bastide, 1961), su evolución ha permitido -en sus vertientes más críticas - una aprehensión sociológica de la realidad donde los sujetos individuales son indisolublemente una parte activa de la construcción de esta, sin dejar de entender los procesos estructurales que la constriñen y constituyen, desligándose cada vez más de sus iniciales determinaciones biologicistas, aunque sin dejar de comprender sus influencias.

Siguiendo la historia del desarrollo de esta perspectiva, se entiende cómo los vínculos entre la epidemiología psiquiátrica y la sociología se estrechan en la comprensión psicoanalítica de la salud mental. A través de esta, se va más allá del uso de la sociología como constructora de técnicas sociométricas útiles para la investigación epidemiológica, es decir, se ponen en relieve los mecanismos a través de los cuales los contextos sociales, en todas sus dimensiones: macro, meso y micros

\footnotetext{
$4 \quad$ Este término es acuñado por la Escuela Psicopatológica de Cambridge como resultado de sus estudios epistemológicos de la psiquiatría como campo de estudio (Luque, 2015).

5 El psicoanálisis en su vertiente "humanista" debe su nombre a Fromm a partir de intentar llevar un paso más lejos la teoría psicoanalítica de Freud al integrar elementos existenciales de la naturaleza humana a la visión freudiana.
} 
objetivas y subjetivas, se interrelacionan con el mundo psíquico de los sujetos individuales y de los grupos que conforman. Una perspectiva psicoanalítica de la dimensión individuo-sociedad la ubica en el espacio heterogéneo que la constituye y solo a partir del cual se pueden interpretar los útiles datos de los estudios epidemiológicos.

En este sentido, la epidemiología y la sociología contemporáneas interesadas en el estudio de la salud mental encuentran en los desarrollos del psicoanálisis herramientas útiles para la aprehensión de las parcelas de las realidades que indagan. El creciente interés de epidemiólogos y sociólogos en nuestra región por el estudio de las determinaciones sociales de los trastornos mentales, y por la construcción de estrategias viables y acertadas para la prevención de estas pueden obtener fundamentos teórico-metodológicos importantes en dichas perspectivas, sobre todo en los desarrollos que las mismas han tenido al interior de la epistemología crítica.

La manera en que esta configuración abstracta de la realidad empírica permite indagar en las correlaciones que se tejen entre la salud mental - comprendida como continuo- y los factores que la moldean, así como la forma en que ella influye en la edificación de diversas situaciones multidimensionales, constituye, sin dudas, un punto de partida para el necesario desarrollo de la investigación en los diversos contextos latinoamericanos. No se puede perder de vista que a dichos contextos los distinguen particularidades regionales de conformación sociohistórica, que divergen de aquellas realidades donde la investigación empírica en el campo - al haber tenido mayor desarrollo moldeado por diversos motivos- han implantado cierta hegemonía epistemológica.

Por esta razón de inicio, la epistemología crítica, en la que se insertan algunos desarrollos importantes del psicoanálisis, es una matriz relevante para los intentos de edificación de investigaciones contextualizadas que vayan en la búsqueda de los nexos relacionales entre mecanismos estructurales y subjetividades individuales y/o colectivas, y para los estudios que profundicen la conformación sociohistórica de las sociedades que han moldeado nuestras identidades y la manera en que sus procesos de construcción se revierten en la edificación de nuevas realidades, ahondando en las implicaciones de dichos procesos sobre el universo psíquico y sus expresiones. 
En este sentido, el rescate del pensamiento fromniano se convierte en un esfuerzo que puede resultar válido. Aunque su contrastación empírica no ha sido suficientemente desarrollada, e incluso algunos han intentado desacreditar la veracidad científica de su perspectiva analítica, las características que cada vez más representan a las sociedades humanas contemporáneas parecen reafirmar las tesis antropológicas y sociológicas de Erich Fromm. Hacer uso de estas como marco analítico para el estudio de la salud mental en nuestros contextos, a partir del andamiaje conceptual de lo que el propio autor denominó psicoanálisis humanista, aunque puede ser un punto de apertura para polémicos debates al respecto, constituye un camino que vale la pena transitar.

\section{El pensamiento contrahegemónico de Erich Fromm: las luces en las sombras de un pensamiento crítico}

En toda la amplia bibliografía de Erich Fromm se constata la consolidación de un pensamiento que se erige contrahegemónico frente a la sociedad que le era contemporánea. Esta evidencia se da no solo por sus acertadas y agudas críticas a estas sociedades, sino además por el esfuerzo continuo de construir una dialéctica negativa que encontró sus orígenes en el proyecto de la Escuela de Frankfurt del Instituto Investigaciones Sociales de la Alemania de 1930. Sin dudas, ello ha constituido uno de los aportes más importantes de los intelectuales que se aglutinaron alrededor del instituto y de los que luego continuaron la búsqueda de un objetivo fundamental: la construcción de una epistemología que hundiera sus raíces y se desarrollara a partir del análisis profundo, crítico y de superación de la teoría social y de la filosofía histórico-materialista (Honneth, 1990).

La conformación de esta epistemología, aunque está lógicamente ligada al contexto sociohistórico e intelectual en el que se origina, logra trascender, desde el punto de vista explicativo, su realidad deviniendo en paradigma analítico (Cebotarev, 2003). Constituye, desde sus comienzos mismos, un conjunto de axiomas teórico-metodológicos que, aunque heterogéneos a su interior, intentan un acercamiento interdisciplinar y multidimensional a aristas disímiles de lo social. Aunque como perspectiva teórica ha tenido momentos de encuentros y (des)encuentros consigo misma y ha sido objeto de múltiples señala- 
mientos, ha evolucionado, perfeccionado y superado lagunas iniciales, permitiendo una visión crítica de las interrelaciones dialécticas entre el individuo y la sociedad. En esta, los sujetos son entes activos en la conformación de sus realidades y, por tanto, son - a pesar de las constricciones estructurales- actores sociales capaces de transformarlas.

Esta lectura contrahegemónica, que caracteriza a la epistemología crítica desde su génesis a partir de la fusión de la teoría social y la filosofía marxista, ha contribuido y es a su vez edificada por claros pensamientos como el de Erich Fromm, cuya contemporaneidad a la vuelta de cuarenta años desde su desaparición física, se presenta insoslayable. Como uno de los más prominentes exponentes de la epistemología crítica de la segunda mitad del siglo XX, el sociólogo psicoanalista intenta indagar en las posibilidades de la libertad humana en un mundo que lo aprisiona cada vez más. La misma preocupación ilustrada que dio inicio a los movimientos intelectuales que permitieron la conformación de las ciencias sociales invade el pensamiento de Fromm desde sus inicios con un resultado que presenta una visión más acabada y optimista: el hombre puede ser capaz de liberarse en la medida en que se encuentre a sí mismo, en la medida en que se dé cuenta de su realidad objetiva y subjetiva, y supere el estado de enajenación en el que la sociedad, con toda su pluralidad, lo sumerge.

Así, para este autor, el papel fundamental de todo intelectual comprometido con su realidad es el de la praxis revolucionaria, es el de mostrar el camino a la libertad. Siguiendo esta meta, se dedica en encomioso esfuerzo toda su vida no solo a señalar lo que hace daño a la humanidad, sino que además busca y apunta maneras de superar tal estado de cosas. Este principio ético y revolucionario, que acompaña a la epistemología crítica desde su génesis, encuentra en Fromm expresión empírica. No se trata solo de la crítica por la crítica, hay un uso de esta orientada hacia el cambio, hacia la transformación.

En consonancia con ello, la mayor contribución del autor de Psicoanálisis de la Sociedad Contemporánea (Fromm, 1964) ha sido tal vez la de mostrar un camino realizable, completamente anclado en la realidad, producto de un análisis profundo de ella. Aunque algunos han intentado desacreditar el pensamiento creador de Fromm, acusándolo de utópico o "a-científico" (Caparros, 1975), sin duda que una revisión de las obras escritas en su madurez intelectual desarticula 
dichas pretensiones. No hay utopía cuando el psicoanalista afirma en Psicoanálisis de la sociedad contemporánea que

el hombre puede protegerse a sí mismo contra las consecuencias de su propia locura, únicamente creando una sociedad sana adaptada a las necesidades del hombre, necesidades que están arraigadas en las condiciones mismas de su existencia; una sociedad en la que el hombre se relacione con el hombre amorosamente, en la que se sienta enraizado en vínculos de fraternidad y solidaridad, más que en los lazos de la sangre y de suelo; una sociedad que le brinde la posibilidad de trascender la naturaleza creando y no destruyendo, en que cada individuo adquiera el sentido de sí mismo, sintiéndose sujeto de sus capacidades, y no mediante la conformidad; en la que exista un sistema de orientación y devoción, sin que el hombre necesite deformar la realidad ni adorar ídolos. Organizar esa sociedad significa dar un nuevo paso, significa el fin de la historia "humanoide", de esa etapa en que el hombre todavía no era plenamente humano. (Fromm, 1964, p. 299).

Muestra así este intelectual un posible camino viable en el que trasciende lo individual en la búsqueda de alternativas que intervengan en la prevención de trastornos mentales. De esta manera, Fromm visualiza en la edificación de una sociedad sana, una vía eficaz para evitar la locura. En este sentido, él apunta en la misma obra que

debe terminar el uso del hombre por el hombre, y la economía tiene que convertirse en la servidora del desenvolvimiento del hombre. El capital debe servir al trabajo, las cosas deben servir a la vida. En vez de la orientación explotadora y acumulativa, predominante en el siglo XIX, y de la orientación receptiva y mercantil predominante en la actualidad, debe ser la "orientación productiva" el fin al cual sirvan todos los dispositivos sociales. (Fromm, 1964, p. 298).

Desarrolla el autor un pensamiento contrahegemónico que orienta hacia una praxis contrahegemónica como el único camino posible para la humanidad de finales del siglo XX, con la esperanza de que esta "despertara" y escogiera la "vida". El letargo en el que las sociedades contemporáneas - en todas sus versiones - han sumido al hombre es, para Fromm (1964), el mayor peligro que ha acosado a la especie humana. “Todo el mundo es 'feliz', salvo que no siente, ni razona, ni ama. 
El problema del siglo XIX fue que 'Dios había muerto'; el del siglo XX es que 'ha muerto el hombre"' (p. 298). El hombre se cree libre, pero camina con pasos agigantados hacia la automatización y la robotización.

Los procesos de enajenación que reproducen los actuales sistemas de mercantilización aprisionan sus necesidades existenciales, las manipulan. Los sujetos se sienten felices cuando tienen cosas, cuando poseen cosas y, en la medida en que el sistema es capaz de proporcionárselo, son "felices"; la patología se vuelve normal en tanto la "racionalidad" de poseer está "bien". Se perfila ya en Fromm la explicación novel de lo que luego otro gran teórico crítico, Habermas, desarrollaría en su teoría sobre la colonización del "mundo de la vida" por parte del "mundo de los sistemas" (Habermas, 1998): el desarrollo de racionalidades aparentemente armónicas entre las estructuras sistémicas y el mundo sociopsicológico de los sujetos, pero que, en la práctica, resultan ser diferentes y contradictorias.

La exhaustiva explicación por parte de Fromm de cómo se producen estos procesos es otro de los aportes importantes del psicoanálisis al pensamiento sociológico, ya que este explica/desarrolla los mecanismos a través de los cuales se interrelacionan lo estructural y lo psicosocial. Desde su concepción sociológica, "para entender la dinámica del proceso social tenemos que entender la dinámica de los procesos psicológicos que operan dentro del individuo, del mismo modo que para entender al individuo debemos observarlo en el marco de la cultura que lo moldea" (Fromm, 1971, p. 24). Constituye así un instrumento relevante para el análisis empírico de múltiples fenómenos de nuestras realidades, fundamentalmente para aquellos que se propongan indagarlos desde una perspectiva multidimensional que trascienda los límites de lo microsociológico. Esta perspectiva invita a la construcción de lecturas que comprendan las causas de las causas más allá de sus condicionamientos inmediatos, y vayan hacia la búsqueda de soluciones que involucren a actores políticos, económicos y sociales.

Para Fromm (2009), "la plena libertad e independencia existen solo cuando el individuo piensa, siente y decide por sí mismo" (p. 67). Devolver a la humanidad esa libertad es, para el autor, la misión de aquellos en los que aún sobrevive un pensamiento humanista. La lucha constante hacia todo lo que limita ese estado ha de caracterizar a las ciencias sociales contemporáneas. Desde su visión, las sociedades 
pueden sanar o pueden enfermar al hombre, por tanto, los esfuerzos deben estar encausados a construir sociedades que sanen. No hay fuera de esto otro camino, y no hay atajos. La deconstrucción de las actuales relaciones de poder que caracterizan a nuestras realidades será el único camino posible. Mientras que un hombre tenga que aceptar impositivamente a vender su fuerza ante la amenaza de su precaria cotidianidad, no habrá libertad posible. En tanto no exista real coparticipación en la toma de decisiones políticas, laborales, sociales, no habrá libertad posible. Para decirlo en los términos de Fromm (1964): "No habrá libertad mientras el propietario de capital pueda imponer su voluntad al hombre que no posee otra cosa que su vida, porque este último, no teniendo capital, no tiene más trabajo que el que le ofrece el capitalista" (p. 276). En tanto, mientras la participación individual y de determinados grupos sociales se limite a ser parte de la distribución de las ganancias en forma de salario, la verdadera libertad seguirá estando coartada.

Por otra parte, y en correspondencia con lo antes expuesto, otra de las contribuciones del autor está en la definición de conceptos como "carácter social" y "necesidades existenciales", que tienen base en su concepción antropológica del hombre y cuyas raíces se perciben sujetadas a la concepción marxista de la naturaleza humana. Fromm dedica varios de sus libros más importantes al desarrollo de estos conceptos. En textos como El miedo a la libertad, El arte de amar, Anatomía de la destructividad humana y el ya citado Psicoanálisis de la sociedad contemporánea deja explícita su certeza de que los hombres, con independencia de los sistemas culturales en los que socialicen su vida, tienen características psicológicas comunes que, aunque constantemente moldeables, los definen como especie, a la vez que dichas características están interrelacionadas con necesidades existenciales vitales.

Al comprender el carácter social, no como la simple sumatoria de caracteres individuales sino como el producto de "la adaptación dinámica de la naturaleza humana a la estructura social" (Fromm, 1971) socio históricamente concebida, dota a la comprensión sociológica sobre las dinámicas sociales de un instrumento válido para interrogar los fenómenos sociales, sin relegar a segundos planos ni lo estructural ni lo individual. Partiendo desde la visión antropológica de que el 
ser humano como especie comparte una naturaleza existencial común que, aunque es moldeada por factores sociales y culturales, es a la vez independiente de estos y los conforman, podemos construir epistemológicamente una visión científica de la realidad social que supera las lagunas del relativismo histórico.

La existencia de necesidades vitales comunes conduce al científico social a la comprensión de la humanidad como especie más allá de las diferencias ineludibles de sus condiciones socioculturales históricamente construidas, y dota a las ciencias que ahondan en estas realidades de parámetros esenciales para la consecución de resultados veraces. El posicionamiento o fromniana subraya así las posibilidades del logro de un conocimiento objetivo del mundo social, de la naturaleza humana. Ello desecha claramente las críticas hechas al mismo sobre la ausencia de un entendimiento científico de la realidad. Solo deviene en otra manera de mirar el entramado relacional que define lo social, consolidando y revitalizando una línea de pensamiento que se aleja del positivismo ortodoxo.

En este sentido, define Fromm un conjunto de necesidades que constituyen, desde su perspectiva, el problema fundamental del hombre: el de buscar y hallar solución a su existencia misma. Para el psicoanalista, la cuestión esencial estriba para los humanos en satisfacer ese conjunto de necesidades que, en interacción con las potencialidades propias inherentes a las personalidades, moldean y son moldeadas por las estructurales sociales resultantes de la evolución histórica. En consonancia con Marx, el hombre es, para Fromm, constructor de su historia y resultado de esta, a la vez que ha conquistado la naturaleza separándose de esta y trascendiéndole, pero de cuya dependencia intrínseca no se puede desligar. Para este autor, "el hombre transforma el mundo que lo rodea, se transforma a sí mismo en el proceso de la historia. El hombre es su propia creación" (Fromm, 1964, p. 19).

Así, Fromm visualiza que en los procesos de construcción del carácter social intervienen necesidades existenciales - materiales y espirituales - como la necesidad de interrelación, de trascendencia, de arraigo, de identidad y de una estructura que lo oriente intelectualmente en el mundo y lo vincule con este, además de aquellas instintivas que están asociadas a la sobrevivencia física del cuerpo como comer, vestir, dormir y tener relaciones sexuales. Pero la distinción relevante 
de Fromm, y en buena medida su ruptura con el biologicismo que define al psicoanálisis freudiano, está en la comprensión de estas necesidades como el resultado de las condiciones de existencia social como producto de esta y no como algo intrínseco a la naturaleza misma del hombre. Este, aunque tiene potencialidades propias que la existencia vital, desarrolla o restringe la conformación de sus necesidades más importantes, y la satisfacción de estas tienen explicación solo en el entendimiento de sus condiciones existenciales. Las necesidades no son, por tanto, biológicamente innatas, sino la derivación de las relaciones que el hombre ha tejido con la naturaleza y con sus semejantes.

En este conjunto de necesidades Fromm ve la fuente fundamental de la que brota todo el conjunto de anhelos, pasiones, afectos y ansiedades humanas, aquellas que se exteriorizan en el comportamiento, en la acción social. Por ello, en la medida en que el hombre es humano, la satisfacción de sus necesidades instintivas y materiales no basta para hacerlo feliz, ello siempre va depender de la manera en que sus condiciones de existencia objetivas y subjetivas han moldeado su psiquis, es decir, aunque tenemos todos necesidades comunes, la forma en que percibimos la satisfacción de estas puede variar en correspondencia con los procesos que han configurado nuestra historia individual y de la colectividad de la que formamos parte. Por lo tanto, las sociedades que quieran seriamente contribuir a la existencia plena del hombre han de tomar en cuenta estas contradicciones inherentes a la condición humana y han de buscar mecanismos estructurales que potencien la creatividad, la participación, la identidad como especie, el apoyo mutuo y el respeto a la adhesión a los más disímiles marcos de orientación ética e intelectual.

En la búsqueda de fundamentos empíricos para el desarrollo de estos conceptos, el padre del psicoanálisis humanista realiza un estudio exhaustivo de los desarrollos de estos a lo largo de la evolución humana, profundizando en la conformación y despliegue de los modos de producción capitalista en sus diversas manifestaciones. Para este autor, las relaciones de producción capitalistas han logrado sobrevivir y reproducirse incluso en los marcos de los sistemas políticos socialistas que han tomado una forma histórica concreta. Aunque ello puede ser objeto de polémicos debates, y este posicionamiento ha conducido a que sea para muchos Fromm un anarquista, resulta sumamente 
interesante la lectura de reflexiones como la que aparecen en un epígrafe del capítulo VII, "Socialismo", de su Psicoanálisis de la sociedad contemporánea. En este apartado, y en las reflexiones finales de esta obra, el autor defiende la idea de que lo más relevante en la comprensión de las formas reales, en las que se ha manifestado el socialismo, no debe estribar en las diferencias que lo distinguen del capitalismo en cuanto a las características de los sistemas de propiedad, sino en el análisis profundo de las relaciones de poder que se despliegan en su interior, apuntando que, en ello, han sido más las similitudes que las diferencias reales, en tanto "mientras los hombres que trabajan no se sientan miembros de una comunidad autónoma de trabajadores, serán esencialmente serviles, sea cualquiera el régimen político en que vivan" (Fromm, 1964). No basta para este autor cambiar los regímenes de propiedad, sino que es imprescindible un profundo cambio en las relaciones de poder. Ahondando en las ideas de pensadores socialistas como D. H. Cole y W. Mellor, sostiene que "existirá esclavitud asalariada mientras haya un hombre o una institución que sea amo de hombres; acabará cuando los trabajadores aprendan a poner la libertad por encima de la comodidad" (Fromm, 1964).

Lo curioso y lo que resulta en un optimismo real, cuando seguimos el análisis de este autor, estriba en que comprende verazmente los obstáculos inherentes al carácter social para la consecución de una sociedad diferente, pero se arriesga en concluir que el hecho de que aún no haya sido posible en la práctica no significa que no pueda serlo. Al buscar y dejar explícitas las maneras en que creía que podía hacerse posible, dedica gran parte de sus estudios y reflexiones a partir de la década del 60, tomando como una de las categorías fundamentales de análisis la del trabajo en sus múltiples dimensiones sociopsicológicas, económicas y culturales.

Asistimos, pues, a través de la lectura de sus escritos a la apertura de un espacio dialógico que invita a la autocomprensión de las realidades que nos son contemporáneas, reflejando en ello la aprehensión del psicoanálisis como un instrumento metodológico que no solo permite penetrar en la psiquis de los otros para comprender los fenómenos sociales, sino en la autognosis de nosotros mismos comprendiéndonos como un producto histórico de dichos contextos. Fromm nos guía a situarnos como intelectuales fuera de nuestra realidad $y$, a la vez, parte 
indisoluble de esta, hallándose, para este defensor de la epistemología crítica, la clave hermenéutica y contrahegemónica de la indagación científica en la visualización del hombre como constructor de su propia historia.

\section{Posibilidades explicativas del psicoanálisis frommniano para el estudio de la salud mental}

Las preocupaciones y la conformación de una perspectiva sociológica-psicoanalítica en Fromm sobre el campo específico de la salud mental se evidencian en obras pioneras como Obreros y empleados en vísperas del tercer Reich, de 1929, y El dogma de Cristo, de 1930; además de sus estudios sobre Sociopsicoanálisis del campesino mexicano: Estudio de la economía y la psicología de una comunidad rural, de 1973, y Tener o ser (1978); y pasando por importantes contribuciones anteriormente abordadas en este artículo como, El miedo a la libertad (1941), El arte de amar (1956) y Psicoanálisis de la sociedad contemporánea en su revisión de 1964. Por tanto, hilvanar en toda su amplitud sus ideas en torno a esta problemática requeriría un análisis que va más allá de las intenciones y los requerimientos formales de esta reflexión. No obstante, se intentará en las próximas líneas esbozar, al menos, los desarrollos más importantes - a la vez controversiales- que han contribuido a una comprensión de la salud mental como continuo. Partimos, por lo tanto, con compartir con este autor una concepción de esta esfera de la salud humana que, lejos de ser "poco específica" o proclive a "ambigüedades", como algunos han considerado, se abre la posibilidad de sobrepasar los límites de lo que se comprende como patológico o no patológico en los marcos de determinadas construcciones socioculturales.

Así, la definición que se perfila desde el psicoanálisis humanista comprende la salud mental no solo como ausencia de enfermedad, ni en su dicotomía biologicista de sano-enfermo, sino como un proceso, como un continuo que puede presentarse en diferentes grados y sobre los que las diferentes ciencias que lo abordan deben actuar. En consecuencia, la conceptualización fromniana de salud mental irradia luz tanto a los caminos dirigidos hacia los procesos clínico-asistenciales como aquellos que cada vez más imprescindiblemente deben encontrar acciones necesarias para la promoción y prevención. Desde su 
mirada, Fromm impregna dicha concepción de un conocimiento profundo y multidimensional del ser humano a partir de la comprensión de sus especificidades biológicas, psicológicas, histórico-sociales y antropológicas.

Tal conceptualización apunta a que el hombre disfruta de salud mental siempre que llegue a su plena madurez de acuerdo con las características de la existencia y las leyes de la naturaleza humana. En este sentido, Fromm define en 1964 que

la salud mental, en el sentido humanista, se caracteriza por la capacidad para amar y para crear, por la liberación de los vínculos incestuosos con la familia y la naturaleza, por un sentido de identidad basado en el sentimiento del yo que uno tiene como sujeto y agente de sus potencias, por la captación de la realidad interior y exterior a nosotros, es decir, por el desarrollo de la objetividad y la razón. La finalidad de la vida es vivirla intensamente, nacer plenamente, estar plenamente despierto. Libertarse de las ideas de grandiosidad infantil, para adquirir el convencimiento de nuestras verdaderas - aunque limitadas - fuerzas; ser capaz de admitir la paradoja de que cada uno de nosotros es la cosa más importante del universo, y al mismo tiempo no más importante que una mosca o una hoja de hierba. Ser capaz de amar la vida y, sin embargo, aceptar la muerte sin terror; tolerar la incertidumbre acerca de las cuestiones más importantes con que nos enfrenta la vida, y no obstante tener fe en nuestras ideas y nuestros sentimientos, en cuanto son verdaderamente nuestros. Ser capaz de estar solo, y al mismo tiempo sentirse identificado con una persona amada, con todos los hermanos de este mundo, con todo lo que vive; seguir la voz de la conciencia, esa voz que nos llama, pero no caer en el odio de sí mismo cuando la voz de la conciencia no sea suficientemente fuerte para oírla y seguirla. La persona mentalmente sana es la que vive por el amor, la razón y la fe, y que respeta la vida, la suya propia y la de su semejante. (p. 172).

Cualquier sociólogo inquietado por el necesario rigor metodológico; o cualquier psiquiatra preocupado por la clínica podría mirar con recelos esta definición, por lo que ¿cómo la operacionalizamos para ir a la consecución de datos específicos en la realidad? o ¿ cómo se evalúa a partir de ella el grado en que está afectada o no la salud de determi- 
nado sujeto individual? La respuesta a estas preguntas debe haber desvelado a más de un médico y/o científico social que se haya acercado esta definición.

Si nos adentramos en la faena metodológica, la cual, dicho sea de paso, ha de aterrizar la abstracción para su utilización y traducción clínica, lo primero que salta a la vista es la síntesis que este concepto presenta de otros dos centrales - ya mencionados en esta reflexión-en la comprensión del autor sobre la dinámica social: el concepto de "carácter social" y el de "necesidades existenciales". Cuando repensamos las dimensiones que el propio autor visualiza al interior de cada uno de ellos, se encuentra que el primero toma forma en la comprensión de que existe una naturaleza humana universal, que encierra en sí misma características psicológicas comunes para la mayoría de los hombres, y que estas están moldeadas por sus condiciones históricas de existencia. A su vez, dichas características psicológicas comunes encuentran expresiones fácticas diferentes en las individualidades de los sujetos en las potencialidades que los identifican.

Por otra parte, al interior del concepto - que puede devenir variable - de necesidades existenciales, visualiza el autor dimensiones como: arraigo, identidad, marco de orientaciones ético-intelectuales, interrelación o necesidad de asociación y de trascendencia, o de sentirse parte activa, sujeto creador. El estudio de una, de varias o de todas las dimensiones que distingue Fromm al interior de estos conceptos ha de orientar cualquier esfuerzo investigativo o clínico que intente situarse en los marcos de referencia de la concepción sobre salud mental anteriormente apuntada. A su vez, la misma tiene el mérito de redireccionar la mirada hacia los nexos entre el continuo salud-enfermedad mental y sus condicionamientos macro, meso y microsociales.

Este enfoque teórico-metodológico entronca directamente con las preocupaciones más contemporáneas de organismos internacionales rectores de las investigaciones y políticas de salud física y mental humana como la Organización Mundial de la Salud y sus dependencias regionales, como la Organización Panamericana de la Salud. Desde finales del siglo XX e inicios del nuevo milenio, las preocupaciones de estas organizaciones por encaminar y desarrollar acciones específicas hacia la prevención, promoción, asistencia y rehabilitación de la salud mental han estado en el centro de sus agendas. Las alarmantes tendencias de 
aumento de las afecciones de esta arista de la salud se han convertido en focos de alerta (Organización Panamericana de la Salud, 2018).

No obstante, a pesar de las planificadas y desplegadas acciones en nuestra región, sobre todo a partir del año 1990, con la conocida Declaración de Caracas y los subsiguientes esfuerzos de reestructuración de los sistemas de atención psiquiátrica, fundamentalmente bajo los preceptos del modelo de Atención Primaria de Salud, entrado el nuevo milenio, las propias organizaciones internacionales reconocen que los desafíos seguían mostrándose muy grandes.

En este sentido, encontramos que, en 2001, a once años de los acuerdos de Caracas, la Organización Mundial de la Salud dedicó su año de trabajo a la búsqueda y puesta en marcha de alternativas posibles a dicho problema epidemiológico. Con este fin, apoyó la preparación e iniciación de nuevas campañas mundiales para el tratamiento y la prevención de varias enfermedades mentales, así como de acciones para prevenir sus consecuencias lamentables. De entre ellas, la conducta suicida y el suicidio consumado habían tomado cifras cada vez mayores (Organización Mundial de la Salud, 2001).

Hacia mediados de esta primera década del nuevo siglo, y como resultado de los esfuerzos que comenzaron a aunarse, se creó hacia 2005, dentro de la Organización Mundial de la Salud, una comisión para visualizar y encaminar iniciativas de diversas índoles dirigidas a luchar contra el impacto de aquellos factores sociales que intervienen en la proliferación de padecimientos mentales. El resultado del aglutinamiento de intelectuales y médicos con este fin resultó en la formulación en 2008 de una guía programática para impulsar el trabajo de la organización y sus dependencias en este sentido (Organización Mundial de la Salud, 2008). Dichos lineamientos, que descansan en una perspectiva teórica que visualiza nítidamente la manera en que las sociedades y la naturaleza intervienen en la sanidad o procesos de enfermedad de los individuos, han impulsado la investigación, la reestructuración de sistemas sanitarios y las acciones de promoción y prevención en esta área de la salud desde inicios de la presente década. Estos han partido de la idea de que

las grandes desigualdades sanitarias entre los países están provocadas por una distribución desigual, a nivel mundial y nacional, del poder, de los ingresos, los bienes y los servicios, y por las consi- 
guientes injusticias que afectan a las condiciones de vida de la población de forma inmediata y visible. (Organización Mundial de la Salud, 2008).

A lo anterior agrega este informe que las inequidades sanitarias "son el resultado de la situación en que la población crece, vive, trabaja y envejece (...), las condiciones en que la gente vive y muere están condicionadas por fuerzas políticas, sociales y económicas". (Organización Mundial de la Salud, 2008). Esta comprensión sobre las implicaciones sociales en la salud física y mental de los seres humanos estaba presente ya en la visión del padre del psicoanálisis humanista y en los desarrollos de una epidemiología latinoamericana que ha hundido sus raíces en la epistemología crítica desde la década de $1960^{6}$.

Ahondar, por tanto, en los desarrollos de esta epistemología en nuestra región, en especial en los aportes que Fromm hizo a la misma, resulta ser necesario dadas las luces que aporta para el estudio multidimensional de la salud mental. Las contribuciones teóricas y metodológicas del autor posibilitan la apertura de rutas aun no transitadas para la investigación empírica en muchos contextos de la región. Estas pueden enriquecer los enfoques más contemporáneos al brindar herramientas útiles para la aprehensión de las realidades a estudiar desde una visión de totalidad.

La manera en que dicha mirada era imprescindible para buscar alternativas de solución a las problemáticas que de salud mental ya sufrían en ascenso las sociedades contemporáneas queda explícita en palabras del propio autor al apuntar en 1964 que "no debe operarse ningún cambio por la fuerza, y debe ser simultáneo en las esferas económica, política y cultural. Los cambios limitados a una esfera destruyen todos los cambios" (Fromm, 1964, p. 299). Pasado medio siglo, dicha perspectiva se pone en el centro de los esfuerzos intelectuales, políticos y científicos para intentar detener y revertir la presente situación epidemiológica sobre salud mental en el mundo.

\footnotetext{
6 Vale aclarar que, aunque es a partir de la década de 1960 que se consolida y desarrolla esta perspectiva en el contexto latinoamericano, está presente en nuestra región desde finales del siglo XIX e inicios del XX en la emergencia de un pensamiento crítico, insurgente y contrahegemónico autóctono en figuras como el psiquiatra, filósofo y sociólogo argentino José Ingenieros o el psiquiatra cubano Gustavo López. Para profundizar al respecto, ver Mariátegui (2000) y Huerta (1991)
} 
Sobran por tanto, las razones por las que resulta notorio ahondar en las contribuciones del psicoanálisis crítico o humanista sobre este campo de estudio. Profundizar en los aportes que recoge la amplia producción bibliográfica del sociólogo alemán y en los desarrollos posteriores de aquellos que afuera y dentro de nuestra región han intentado recuperar y consolidar su perspectiva ${ }^{7}$ no debe ser soslayado por los esfuerzos encaminados a entender las situaciones epidemiológicas contextuales específicas sobre esta problemática. Para la sociología de la salud latinoamericana, la epidemiología crítica y sus incipientes desarrollos en Cuba, constituye esta una perspectiva que ha de ensanchar sus horizontes.

\section{Una última reflexión}

Afirmó Aniceto Aramoni, discípulo y colega de Fromm en México, que el psicoanalista tuvo una vez la certeza de que su obra sería más leída un cuarto de siglo después de su muerte (Castro, 2000). Tal acertada premonición se debió tal vez a que comprendió - como pocos- hacia dónde se dirigía el hombre y la(s) sociedad(es) que construía. Efectivamente, a la vuelta del siglo el interés por las reflexiones de este autor emergió. Aunque pasadas casi dos décadas, aún son muy escasas las investigaciones empíricas que intentan utilizar sus categorías de análisis para el estudio empírico de la realidad que interpretó.

La mayoría de las aproximaciones al autor se han centrado en reconstruir sociohistóricamente su vida y su obra (Avilés, 2014; Funk, 2006; Rivas, 2013; Silva, 2006), así como intentar profundizar en los aportes y limitaciones epistemológicas de sus análisis (Avilés, 2014; Caparros, 1975; de la Fuente, 1980; Peris, 2007; Santoyo, 1993). Caminar más allá de estas primeras contribuciones avalaría los argumentos construidos y permitiría un más acabado acceso al entendimiento de problemáticas urgentes, como la salud mental, desde esa visión imprescindible a la totalidad biopsicosocial, ambiental y trascendental de lo humano.

\footnotetext{
En este sentido, los esfuerzos más notables se han realizado desde el Instituto Internacional Erick Fromm, con sede en Alemania, creado por varios de sus más lúcidos discípulos y cuyo desarrollo en la actualidad es notable. Importantes contribuciones se han realizado también desde el Instituto Mexicano de Psicoanálisis, resultado del Grupo Mexicano de Psicoanálisis creado por Fromm en 1953 cuando se fue a vivir a México, país donde escribió muchos de sus mejores libros y de donde se irradió su filosofía luego hacia otros países latinoamericanos. Ver Castro (2000) y Avilés (2014).
} 
Consolidar la configuración de espacios para el diálogo entre médicos y científicos sociales en países de nuestra región resulta pertinente. Favorecer los acercamientos de la sociología al estudio de la salud mental en contextos en los que, como el cubano, aún prevalecen enfoques biológicos -positivistas permitirá una comprensión más integral a problemáticas cuyas génesis y consecuencias van más allá de la individualidad. Un mayor acercamiento a desarrollos psicoanalíticos de autores como Erich Fromm pueden proporcionar herramientas útiles para el análisis empírico en este campo de estudio. Aunar esfuerzos, en este sentido, sería un paso más hacia la búsqueda de alternativas para la edificación de realidades que no limiten o trunquen el desarrollo de la existencia humana y que estén más cercanas al tipo de sociedad que ha de sanar en lugar de enfermar.

\section{Referencias}

Avilés, N. (2014). Psicoanálisis en México: Una aproximación. (Tesis de licenciatura). Departamento/Escuela de Psicología, Universidad Nacional Autónoma de México, México D.F.

Bastide, R. (1961). Psicoanálisis y sociología. Buenos Aires: Fondo de Cultura Económica.

Borges, G., Medina-Mora, M. E. \& López-Moreno, S. (2004). El papel de la epidemiologia en la investigación de los trastornos mentales. Salud Publica de México, 46(5), 451-463. Recuperado de http://www.scielo.org.mx/scielo.php?script=sci_ arttext\&pid=S0036-36342004000500011\&lng=es\&tlng=es.

Breilh, J. (2003). Epidemiologia crítica. Ciencia emancipadora e interculturalidad. Buenos Aires: Lugar Editorial.

Caparrós, A. (1975). El carácter social según Erich Fromm. Salamanca: Sígueme.

Castro, J. A. (2000). En su centenario, Erich Fromm, en el diván de sus discípulos. Proceso, 1222. Recuperado de http://www.psicomundo.org/fromm/fromm.htm

Cebotarev, E. (2003). El enfoque crítico: Una revisión de su historia, naturaleza y algunas aplicaciones. Revista Latinoamericana de Ciencias Sociales, Niñez y Juventud, 1(1), 17-56. Recuperado de http://www.scielo.org.co/scielo. php?script=sci_arttext\&pid=S1692-715X2003000100002\&l ng=en\&tlng=es. 
De la Cuesta, P., Díaz, A. \& Vaeza, R. (2009). Perspectiva psicológica en salud. Montevideo: Psicolibros.

De la Fuente, R. (1980). La obra de Erich Fromm: Conceptos fundamentales y proyecciones. Salud Mental, 5(2), 3-7. Recuperado de http://www.scielo.org.mx

Freud, S. (1991). VI. Psicopatologia de la vida cotidiana (1901). Buenos Aires: Amorrortu.

Fromm, E. (1929). Obreros y empleados en visperas del tercer reich: un analisis psicologico-social. Buenos Aires: Fondo de Cultura Económica.

Fromm, E. (1941). El miedo a la libertad. Buenos Aires: Paidós.

Fromm, E. (1956). El arte de amar. Buenos Aires: Paidós.

Fromm, E. (1964). Psicoanálisis de la Sociedad Contemporánea. Buenos Aires: Fondo de Cultura Económica.

Fromm, E. (1964). El dogma de Cristo y otros ensayos sobre religión, política y cultura. Buenos Aires: Paidós.

Fromm, E. (1971). El miedo a la libertad. Buenos Aires: Paidós.

Fromm, E. y Maccoby, M. (1973). Sociopsicoanálisis del campesino mexicano: Estudio de la economía y la psicología de una comunidad rural. Buenos Aires: Fondo de Cultura Económica.

Fromm, E. (1978). ¿Tener o ser? Buenos Aires: Fondo de Cultura Económica.

Fromm, E. (2009). La condición humana actual. Buenos Aires: Paidós.

Funk, R. (2006). La vigencia de la obra de Erich Fromm. En J. Silva García (Coord.), El humanismo de Erich Fromm: Actualidad del autor del "Arte de amar" y "El miedo a la libertad" (pp. 3750). Barcelona: Paidós.

Guinsberg, E. (2017). Psicoanálisis en Cuba hoy. Subjetividad y Cultura, 10-12. Recuperado de http://subjetividadycultura.org. $\mathrm{mx} / \mathrm{psicoanalisis-en-cuba-hoy/}$

Habermas, J. (1998). Teoría de la acción comunicativa, II. Madrid: Taurus.

Honneth, A. (1990). La Teoría crítica. En A. Giddens y J. Turner. (Eds.), La teoría social hoy (pp. 445-488). Madrid: Alianza Editorial.

Huerta, R. (1991). Sobre los orígenes de la psiquiatría cubana: la obra de Gustavo López (1860-1912). Asclepio, II(91), 69-87.

Luque, R. (2015). Hacia una nueva epistemología psiquiátrica. Revista Latinoamericana de Psicopatologia Fundamental, 18(3), 566-571. 
Marcuse, H. (1984). Eros y civilización. Barcelona: Ariel.

Mariátegui, J. (2000). Prensa psiquiátrica latinoamericana. Revista de Neuro-Psiquiatría, LXIII(3-4), 138-152.

Montejo, F. J. (2009). El psicoanálisis 1919-1933: Consolidación, expansión e institucionalización. (Tesis doctoral). Facultad de Filosofía, Departamento de Filosofía IV (Teoría del Conocimiento e Historia del Pensamiento), Universidad Complutense de Madrid.

Organización Mundial de la Salud. (2001). Salud mental: Nuevos conocimientos, nuevas esperanzas. (Informe sobre la salud en el mundo). Recuperado de http://www.who.int

Organización Mundial de la Salud. (2008). Subsanar las desigualdades en una generación: Alcanzar la equidad sanitaria actuando sobre los determinantes sociales de la salud. Recuperado de https://apps.who.int/iris/handle/10665/69830h

Organización Panamericana de la Salud. (2018). La carga de los trastornos mentales en la región de las Américas. Washington, D.C.: OPS.

Organización Panamericana de la Salud \& Organización Mundial de la Salud. (2017). Estado de salud de la población: La salud mental en la región de las Américas. Recuperado de https:// www.paho.org/salud-en-las-americas-2017/?post_t_es=lasalud-mental-en-la-region-de-las-americas\&lang=es

Peris, M. (2007). Erich Fromm. Sociedad, vida y teoría. Su relación con la Escuela de Frankfurt. (Tesis de magíster). Universidad Complutense de Madrid.

Ruitenbeck, H. (1973). Psicoanálisis y ciencias sociales. México D.F.: Fondo de Cultura Económica.

Santoyo, J. M. (1993). La teoría ético-humanista de Erich Fromm. Moralia, 15(3-4), 401-428.

Silva García, J. (Coord) (2006). El humanismo de Erich Fromm: actualidad del autor del "Arte de amar" y "El miedo a la libertad". México D.F.: Paidós.

Rivas, R. (2013). Erich Fromm: bases para una antropología paradójica y una ética "negativa". En-claves del pensamiento 7(14), 103-122. 